Report No. BMI-1444

UC-25 Metallurgy and Ceramics

(TID-4500, 15th Ed.)

Contract No. W-7405-eng-92

APPARATUS FOR THE STUDY OF FISSION-GAS RELEASE

FROM NEUTRON-ACTIVATED FUELED GRAPHITE

by

Harvey S. Rosenberg

Robert Lieberman

Duane N. Sunderman

Ward S. Diethorn

J une 7,1960

BATTELLE MEMORIAL INSTITUTE

505 King Avenue

Columbus 1, Ohio 


\section{DISCLAIMER}

This report was prepared as an account of work sponsored by an agency of the United States Government. Neither the United States Government nor any agency Thereof, nor any of their employees, makes any warranty, express or implied, or assumes any legal liability or responsibility for the accuracy, completeness, or usefulness of any information, apparatus, product, or process disclosed, or represents that its use would not infringe privately owned rights. Reference herein to any specific commercial product, process, or service by trade name, trademark, manufacturer, or otherwise does not necessarily constitute or imply its endorsement, recommendation, or favoring by the United States Government or any agency thereof. The views and opinions of authors expressed herein do not necessarily state or reflect those of the United States Government or any agency thereof. 


\section{DISCLAIMER}

Portions of this document may be illegible in electronic image products. Images are produced from the best available original document. 


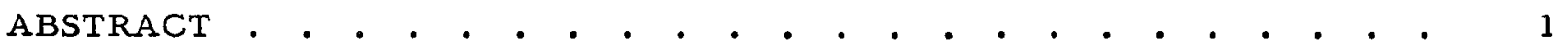

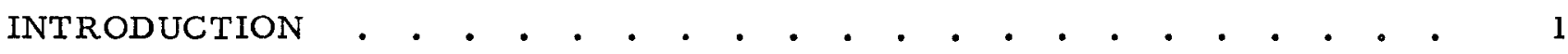

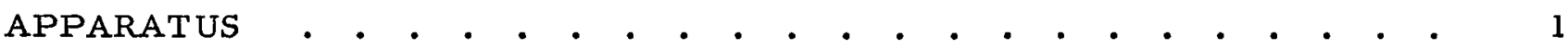

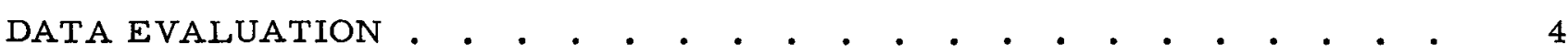
TYPICAL RESULTS • • • • • • • • • • • • • • • • • • • 


\title{
APPARATUS FOR THE STUDY OF FISSION-GAS RELEASE FROM NEUTRON-ACTIVATED FUELED GRAPHITE
}

\author{
Harvey S. Rosenberg, Robert Lieberman, Duane N. Sunderman, \\ and Ward S. Diethorn
}

\begin{abstract}
A simple laboratory apparatus for the study of fission-gas release from neutron-activated fueled graphite was developed. Xenon-133 released from a heated specimen is carried in a helium sweep gas to a charcoal trap, where the accumulated activity is monitored continuously by a scintillation detector, ratemeter, and pen recorder. The maximum specimen temperature $(2500 \mathrm{~F})$ is achieved in 10 min with an induction heater. All instrumentation is commercially available.
\end{abstract}

Data for several neutron-activated fueled-graphite specimens heated in the range from 800 to $2500 F$ are presented to illustrate the typical results obtained with the apparatus.

\section{INTRODUCTION}

A dispersion of $\mathrm{UO}_{2}$ or uranium carbide in graphite is one of the promising nuclear fuel concepts receiving considerable emphasis in the current search for better high-temperature fuel elements. Graphite has the advantages of good thermal and mechanical properties and a well-established fabrication technology. An important area meriting more investigation is fission-product release. Current information in this area does not provide a satisfactory basis for the appraisal of coolant contamination and the associated problem of coolant-loop maintenance in high-temperature reactors.

The study of fission-gas release from neutron-activated fueled graphite can provide useful information on the effect of temperature, coatings, and release mechanisms. This type of study is being carried out in continuing Battelle research in support of the Pebble Bed Reactor (PBR), which is being studied by Sanderson \& Porter for the USAEC. At Battelle, coated fueled-graphite spheres showing good xenon-133 retention in neutron-activation experiments are advanced to static- and sweep-capsule irradiations in the BRR. The purpose of this report is to describe the design and operation of the simple laboratory apparatus used in the neutron-activation experiments. It is believed that the techniques and typical results reported here will be of general interest to others investigating fission-product release.

\section{APPARATUS}

The apparatus is designed to measure continuously the cumulative amount of xenon-133 (half-life $=5.3$ days) released during postirradiation heating. Several days after neutron activation this gamma emitter is the major component in fission gas and 
is readily identified and assayed with scintillation-counter techniques. In the design of the apparatus, temperature capabilities up to $2500 \mathrm{~F}$, sensitivity, simplicity, compactness, and, insofar as possible, the use of commercially available instrumentation were the main considerations. The apparatus is located in a California-type vacuum-frame hood. The power source for the induction heater is located outside the hood.

The apparatus is shown in Figure 1. Tygon tubing is used to join parts of the apparatus which operate at ambient temperature when vacuum requirements permit it. For the components subject to high temperatures, glass or Vycor construction is necessary. Fueled-graphite spheres, 1.5 in. in diameter, are heated rapidly to temperature in a vertical Vycor tube surrounded at the lower end by a copper induction coil. The sphere rests on one end of a hollow graphite sleeve. A Chromel-Alumel thermocouple is positioned about $1 / 8 \mathrm{in.} \mathrm{away} \mathrm{from} \mathrm{the} \mathrm{sphere.} \mathrm{This} \mathrm{thermocouple} \mathrm{penetrates} \mathrm{the}$ wall of the Vycor tube and is located along the center line of the sleeve. A 6-kw AjaxNorthrup high-frequency converter supplies power to the coil. Power input to the coil is controlled by resistors in parallel with the coil. A maximum thermocouple temperature of $2500 \mathrm{~F}$ can be achieved in $10 \mathrm{~min}$.

Two checks were used to determine the accuracy of this method of measuring sphere temperature. The thermocouple temperature was compared with an optical pyrometer reading on the sphere viewed through the Vycor wall and a second thermocouple was embedded in a dummy graphite sphere. These readings were compared with the external thermocouple. For the same power input to the coil, the external thermocouple read about the same as the internal thermocouple and the (corrected) pyrometer up to temperatures of about $2400 \mathrm{~F}$. It is believed that the external thermocouple is reliable to within $50 \mathrm{~F}$.

As-received Bureau of Mines helium flows over the sphere, through a spiral cold trap, and into the charcoal trap within a scintillation crystal where the xenon- 133 is adsorbed. The helium passes through a second charcoal trap (the backup trap) before it is released to the exhaust. All traps are cooled with dry ice. Occasionally water, organic matter, and volatile solid fission products are distilled from the spheres, and these are removed in the spiral trap.

The backup trap provides additional trapping capacity when large amounts of xenon- 133 are released rapidly from the sphere. A mercury relief valve open to the atmosphere prevents accidental pressure buildup in the system. Prior to each run the charcoal is degassed by flaming the traps under vacuum.

The quantity of xenon- 133 deposited in the trap is recorded continuously with a well-type scintillation crystal and ratemeter-recorder. A steel box lined with foam insulation surrounds the crystal and contains dry ice. Two inches of lead on the top and four sides of the box shield the crystal from stray radiation. A cylindrical polyethylene sleeve is placed over the canned crystal to prevent contact with the dry ice. The following equipment is used to measure the xenon- 133 activity:

(1) Harshaw 2 by 1.75-in. well-type NaI(T1) crystal, Type F

(2) Nuclear-Chicago scintillation probe, Model DS5

(3) Nuclear-Chicago count-rate meter, Model 1620

(4) Nuclear-Chicago rectilinear chart recorder, Model R-1000. 


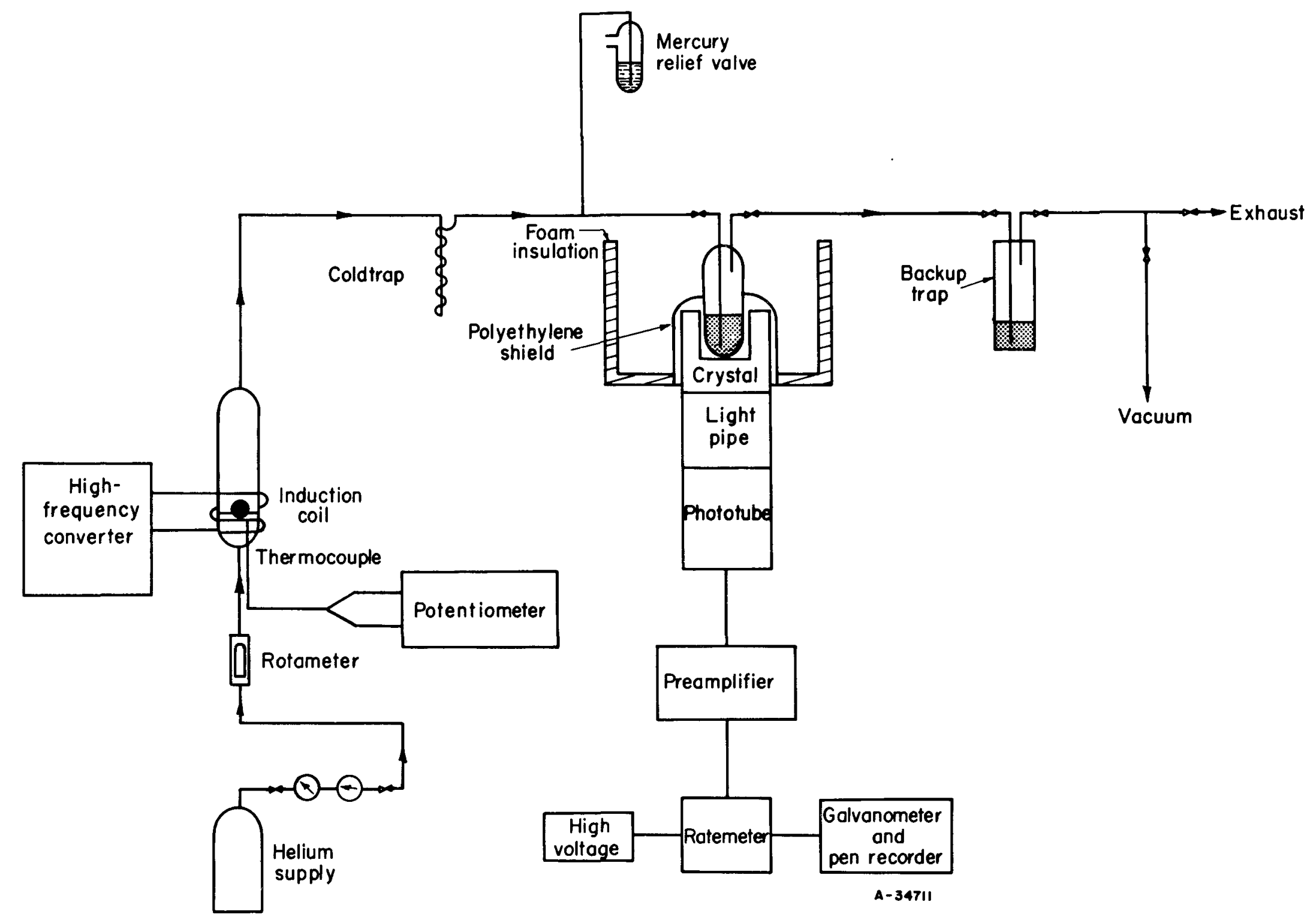

FIGURE 1. APPARATUS FOR MEASURING FISSION-GAS RELEASE 
A 3 by $1.75-$ in. Lucite light pipe is used to couple the crystal face to the phototube. A thin layer of silicone grease separates the pipe and phototube. Grease is not used at the crystal-pipe interface. The pipe is wrapped with aluminum foil. Electrical "pickup" from the induction-heater power supply is avoided by wrapping the steel box and probe leads with aluminum foil.

The negative output from the preamplifier (gain $=10$ ) is fed into the ratemeter amplifier (gain $=50$ ) and sent to the pen recorder. Input sensitivity and time constant of the ratemeter are $0.25 \mathrm{v}$ and $2 \mathrm{sec}$, respectively. The recorder chart provides a continuous time record of the cumulative xenon-133 released from the fueled-graphite sphere. The phototube is operated at $1450 \mathrm{v}$. At this voltage all pulses greater than $20 \mathrm{kev}$ are counted. The two photopeaks of xenon-133 from the internal-conversion $\mathrm{X}$-ray and the primary gamma are 30 and $81 \mathrm{kev}$, so almost all the activity is counted. When the charcoal trap is free of fission gas, the background is $3 \times 10^{4} \mathrm{cpm}$. The ratemeter amplifier begins to saturate when the xenon- 133 counting rate exceeds $7 \mathrm{x}$ $10^{4} \mathrm{cpm}$. The amount of xenon-133 activity in the trap is usually small enough to avoid counting-rate losses.

The detection sensitivity for the 30- and 81-kev xenon-133 photopeaks depends on the trap-wall material. The wall of the stainless steel trap is 40 mils thick. For a $40-\mathrm{mil}$ wall, the ratio of the $30 \mathrm{kev}$ and $8 \mathrm{l}-\mathrm{kev}$ transmissions are 469 and 1.40 for the glass and stainless steel, respectively. The $30-\mathrm{kev}$ peak is not observed with this wall thickness of stainless steel. For this reason, the well trap is made of glass.

When the trap activity is low the sensitivity of the apparatus is limited by the background. The apparatus is not operated in a low-background area and so the best sensitivity has not been achieved. Some improvement in sensitivity could be expected if a single-channel spectrometer were used in the energy region having the optimum sample-to-background ratio. In the work reported here, the gain in sensitivity did not warrant the use of a spectrometer. Undoubtedly, a greater improvement in sensitivity can be achieved by refrigerating the phototube because thermal noise is a major component of the background at the low energy threshold of $20 \mathrm{kev}$.

\section{DATA EVALUATION}

Specimens are neutron activated in a closed can in the weasel tube of the BRR. A cobalt-wire dosimeter is irradiated with each specimen. After cooling in the reactor pool for several days, the specimens are removed for the release study. This cooling period allows short-lived fission products to decay, and reduces the radiation hazard and associated handling problems. Integrated exposures of $10^{14} \mathrm{nvt}$ produce adequate amounts of xenon-133 for the release measurements. Both natural and fully enriched specimens have been examined in the apparatus.

In the postirradiation studies it is convenient to express the release of xenon- 133 as a percentage of the total xenon-133 in the sphere at the beginning of the heat treatment. The familiar Bateman solution gives the following equation for the number of xenon-133 atoms present in the sphere following instantaneous formation of iodine-133 during fission. 


$$
N_{2}=\frac{N_{235} \phi \sigma \mathrm{TY}}{\lambda_{2}}\left[\frac{\lambda_{1} \lambda_{2}}{\lambda_{2}-\lambda_{1}} e^{-\lambda_{2} t}-\frac{\lambda_{1}^{2}}{\lambda_{2}-\lambda_{1}} e^{-\lambda_{1} t}\right],
$$

where

$$
\begin{aligned}
\mathrm{N}_{2} & =\text { number of xenon-133 atoms } \\
\mathrm{N}_{235} & =\text { atoms of uranium-235 } \\
\phi & =\text { neutron flux, nv } \\
\sigma & =\text { fission cross section, } \mathrm{cm}^{2} \\
\mathrm{~T} & =\text { irradiation time, sec } \\
\mathrm{Y} & =\text { cumulative fission yield of iodine-133 } \\
\lambda_{2} & =\text { decay constant of xenon-133, days }-1 \\
\lambda_{1} & =\text { decay constant of iodine-133, days }-1 \\
t & =\text { time after irradiation, days. }
\end{aligned}
$$

After a 4-day decay period, the second term in the brackets is less than 10 per cent of the first term, and can be neglected. Simplification of Equation (1) gives

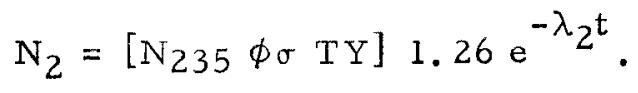

The number of xenon-133 atoms in the well trap is calculated from the observed trap activity, decay constant, and detection efficiency. A standard source of xenon-133 is used to determine the total efficiency of the counting system in Figure 1. The efficiency is 70 per cent. Based on this efficiency, I cpm on the recorder chart is equivalent to $1.6 \times 10^{4}$ atoms of xenon- 133 .

\section{TYPICAL RESULTS}

Results for a few specimens are presented in Figures 2 through 6. Accumulated xenon-133 activity in the well trap is plotted as a function of time. These curves are obtained after subtracting counter background from the recorder charts. Specimen description is summarized in Table 1. The spheres are admixtures of fuel particles and graphite, and contain about $5 \mathrm{~g}$ of uranium.

All of the fueled-graphite spheres were procured from commercial vendors. Figures 2, 3, and 4 show the effect of temperature on the release from a bare fueledgraphite sphere (FA-1). This sphere was neutron activated once and heat treated on 


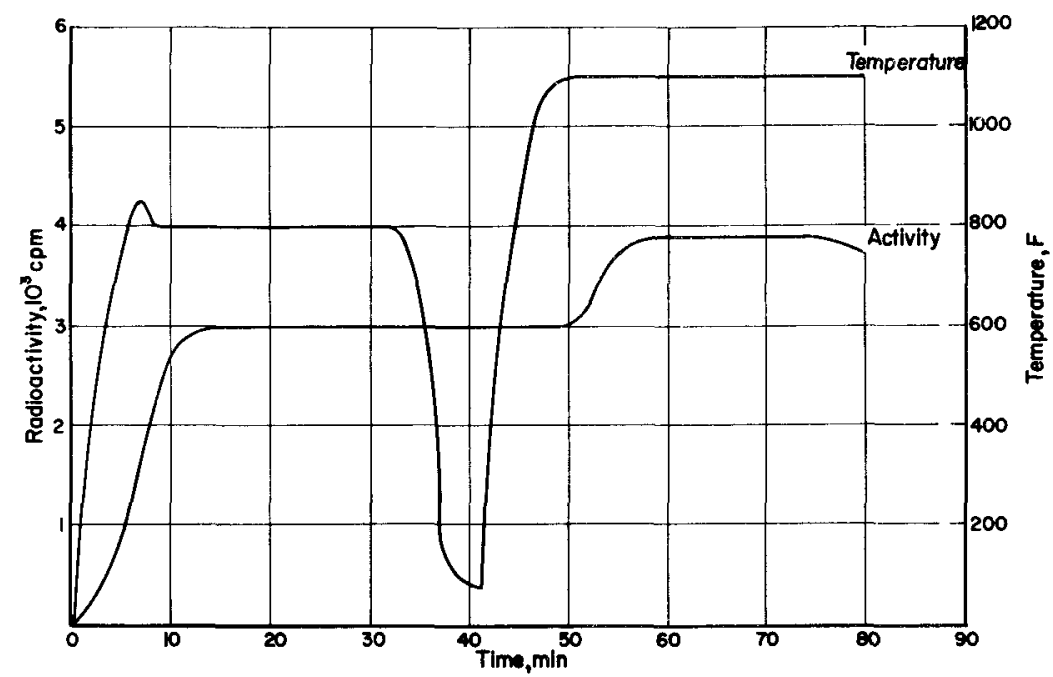

FIGURE 2. CUMULATIVE FISSION-GAS RELEASE FOR SPECIMEN FA-1 AT 800 AND $1100 \mathrm{~F}$

Release at $800 \mathrm{~F}$ was 0.4 per cent; at $1100 \mathrm{~F}$ it was 0.1 per cent.

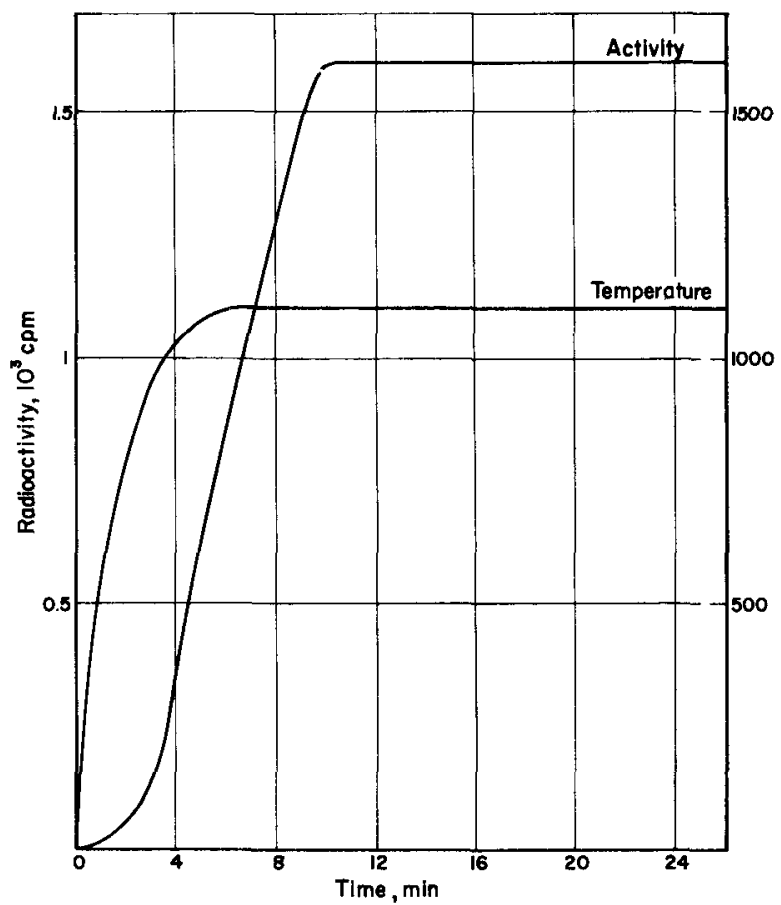

FIGURE 3. CUMULATIVE FISSION-GAS RELEASE FOR SPECIMEN

- FA-1 AT $1100 \mathrm{~F}$

Release was 0.3 per cent.

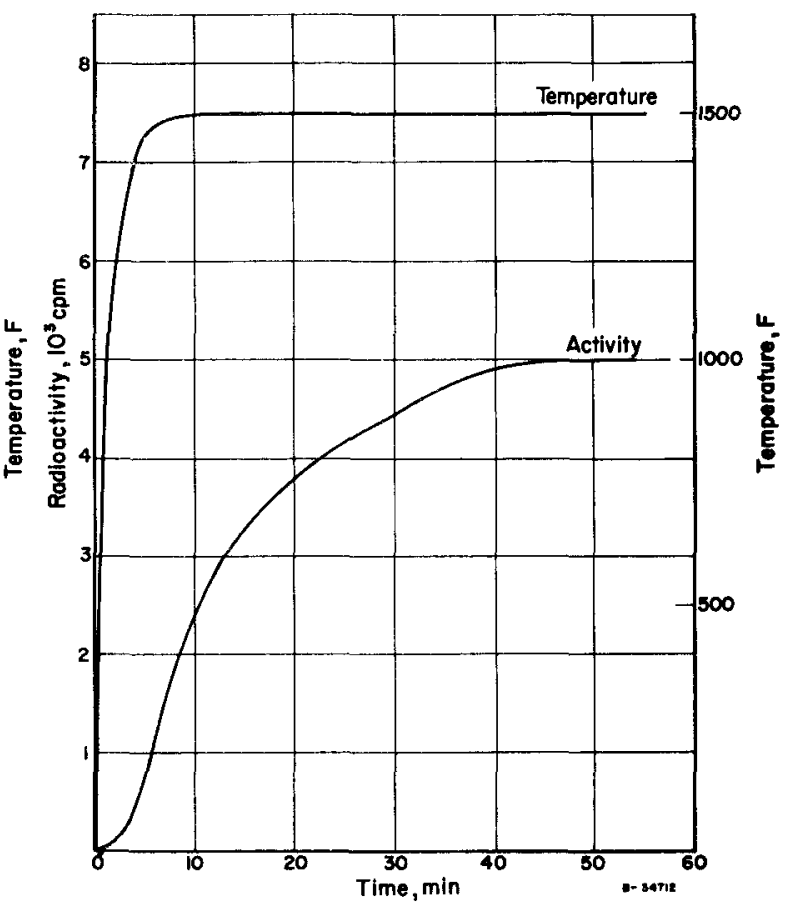

FIGURE 4. CUMULATIVE FISSION-GAS RELEASE FOR SPECIMEN FA-1 AT $1500 \mathrm{~F}$

Release was 0.9 per cent. 


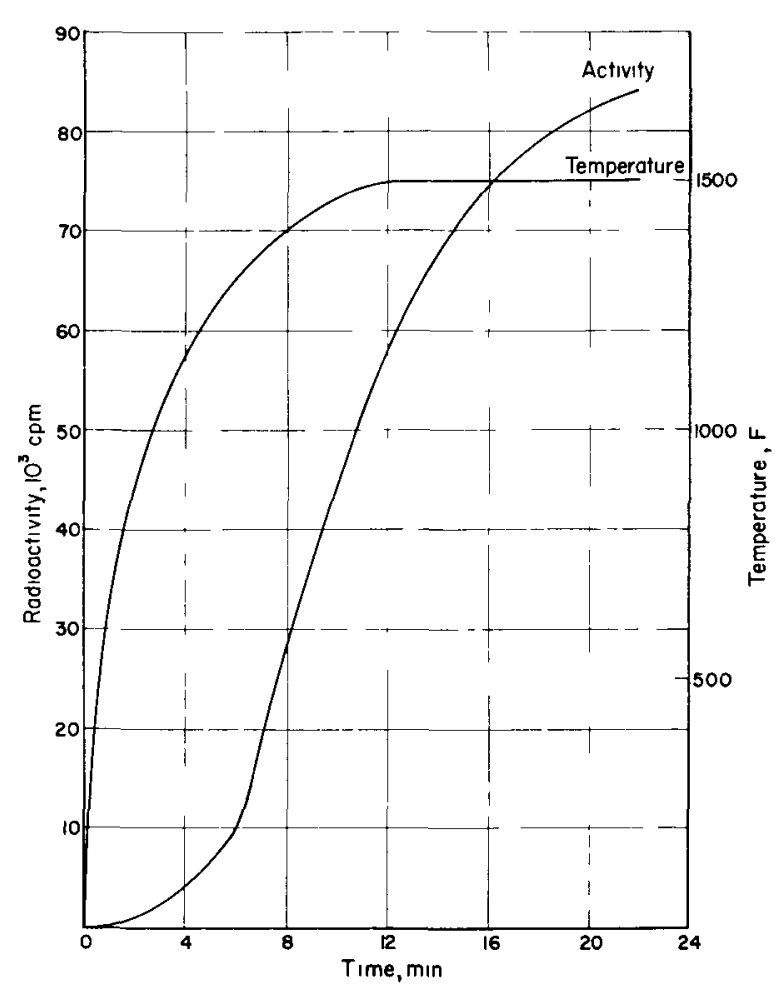

FIGURE 5. CUMULATIVE FISSION-GAS RELEASE FROM DEFECTED SPECIMEN FA- 8 AT $1500 \mathrm{~F}$

Release at 16 min was 0.4 per cent.

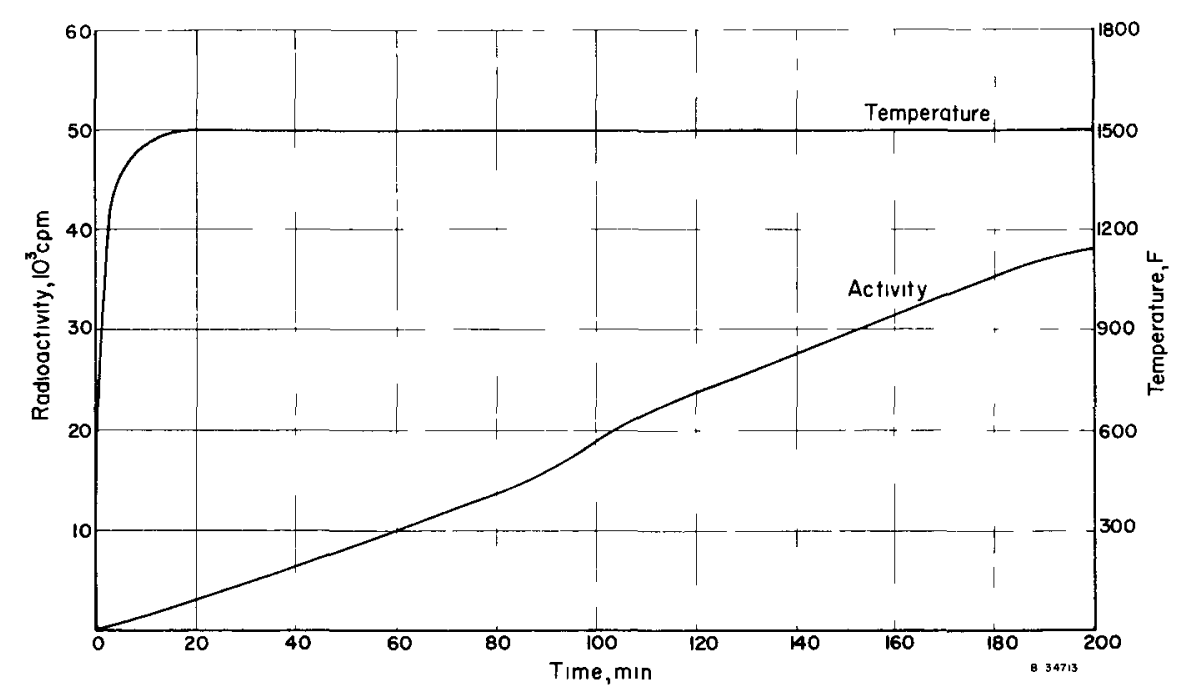

FIGURE 6. CUMULATIVE FISSION-GAS RELEASE FROM SPECIMEN FA-20 AT $1500 \mathrm{~F}$

Release was 0.03 per cent. 
TABLE 1. DESCRIPTION OF FUELED-GRAPHITE SPECIMENS

\begin{tabular}{lcccc}
\hline & \multicolumn{2}{c}{ Fuel Particle } & \multicolumn{2}{c}{ Sphere Coating } \\
\cline { 2 - 3 } \cline { 4 - 5 } Specimen & Type & Diameter, $\mu$ & Type & Thickness, mils \\
\hline FA-1 & $\mathrm{UO}_{2}$ & $100-150$ & & None \\
FA-8 (a) & $\mathrm{UC}_{2}$ & $100-200$ & SiC-silicon & 30 \\
FA-20 & $\mathrm{UC}_{2}$ & $100-150$ & Carbon & 2 \\
\hline
\end{tabular}

(a) Sphere coating defected with 30 -ulit hole.

successive days in the temperature sequence presented in the figures. The rate of release approached zero soon after the sphere reached constant temperature. Duplicate $1100 \mathrm{~F}$ runs (Figures 2 and 3) showed that the temperature effect is not simple. In Figure 2 a plateau is apparent in the activity curve at $1100 \mathrm{~F}$ but, in the second $\mathrm{run}$ at this temperature (Figure 3), the sphere released a considerable amount of additional xenon- 133.

When an exterior coating on a fueled-graphite sphere fails, the xenon- 133 release is comparable to that for an uncoated sphere. Figure 5 shows the results for a coated sphere defected with a 30-mil hole. An ultrasonic technique was used to drill this hole through the $30-\mathrm{mil}$ coating, exposing the graphite matrix. The leveling off that can be observed in Figure 5 is not real. Ratemeter saturation at high counting rates, previously discussed, is responsible for this apparent approach to a plateau value.

The effect of a pyrolytic carbon coating on the release from a sphere is shown in Figure 6. The coating is applied by the high-temperature pyrolysis of a hydrocarbon in the presence of the bare sphere. Dense coatings can be prepared by this method. The quality of the coating on this sphere was fair. Presumably, xenon-133 diffused through the coating by lattice or fine-pore diffusion.

HSR:RL:DNS:WSD/apo 